\title{
COMPORTAMENTO IN VITRO DO AGENTE ETIOLÓGICO DA FUSARIOSE E AVALIAÇÃO DE MÉTODOS DE INOCULAÇÃO EM ABACAXIZEIRO ${ }^{1}$
}

\author{
WANDREILLA MOREIRA GARCIA ${ }^{2 *}$, WILLIAN KRAUSE ${ }^{3}$, DEJÂNIA VIEIRA DE ARAÚJO ${ }^{3}$, \\ CELICE ALEXANDRE SILVA ${ }^{3}$, ANDERSON FERNANDES DE MIRANDA $^{3}$
}

\begin{abstract}
RESUMO - O presente estudo objetivou avaliar o comportamento in vitro do fungo Fusarium guttiforme em condições de temperatura e luminosidade distintas e determinar o método de inoculação mais eficiente para a avaliação da resistência de abacaxizeiro à fusariose. Para a determinação do comportamento in vitro foram realizados dois experimentos utilizando para cada o delineamento inteiramente casualizado, em esquema fatorial $3 \times 3$ (três temperaturas e três regimes de luminosidade), com cinco repetições para avaliação do índice de crescimento micelial e produção de conídios. As avaliações dos métodos de inoculação foram realizadas em delineamento inteiramente casualizado, com arranjo fatorial 3x4 (métodos x distância de inoculação) a partir de folhas " $D$ " de abacaxizeiro da cv. Pérola, inoculadas a 2, 5, 8 e 11 centímetros da base pelos métodos palito infestado com estruturas do patógeno, disco de micélio sem ferimento e disco de micélio com ferimento na folha. Não houve diferença significativa no comportamento in vitro dos isolados analisados. A temperatura e fotoperíodo recomendadas para a multiplicação de $F$. guttiforme foram de $25^{\circ} \mathrm{C}$ e 12 horas, respectivamente, por apresentar maior índice de crescimento micelial e produção conídios. O método indicado para avaliação de resistência à fusariose do abacaxizeiro por meio de inoculação foi o palito infestado com estruturas do patógeno, a uma distância de 2 a $11 \mathrm{~cm}$ da base da folha. Para que ocorra infecção do patógeno $F$. guttiforme faz-se necessário a realização de ferimento no local a ser inoculado.
\end{abstract}

Palavras-chave: Fusarium guttiforme. Ananas comosus var. Comosus. Resistência.

\section{BEHAVIOR IN VITRO OF THE FUSARIUM GUTTIFORM AND EVALUATION OF THE INOCULATION METHODS IN THE LEAVES OF PINEAPPLE}

\begin{abstract}
This study aimed to evaluate the in vitro behavior of the fungus Fusarium guttiform in different conditions of temperature and luminosity and determine the most efficient inoculation method for evaluating the resistance of pineapple to fusariosis. To determine the in vitro behavior, two experiments was performed, with the same design, conduction, and evaluation. It was used a completely randomized experimental design in a factorial arrangement of $3 \times 3$ (three temperatures and three light regimes), with five replications. The evaluations of inoculation methods were conducted in a completely randomized design with factorial arrangement $3 \times 4$ (methods $x$ distance of inoculation). D leaves of pineapple, cultivar Pearl, were inoculated at two, five, eight and eleven centimeters from the base by the methods of infected toothpick, mycelium disc without injury and mycelium disc with injury on the leaf. There was no significant difference on in vitro behavior of the isolates analyzed. The indicated temperature and luminosity for the multiplication of $\mathrm{F}$. guttiform were $25^{\circ} \mathrm{C}$ and 12 hours, respectively, since they showed significant my celial growth and increased production of reproductive structures. The indicated method for evaluation of resistance to fusariosis in pineapple was the inoculation by infected toothpick at a distance between $2-11 \mathrm{~cm}$ from the base of the leaf. It becomes necessary to perform an injury at the site to be inoculated for the infection of the pathogen $F$. guttiform occurs.
\end{abstract}

Keywords: Fusarium guttiform. Ananas comosus var. comosus. Resistance.

\footnotetext{
*Autor para correspondência

${ }^{1}$ Recebido para publicação em .12/04/2014; aceito em 13/05/2015.

Parte da Dissertação de Mestrado em Genética e Melhoramento de Plantas - UNEMAT do primeiro autor.

${ }^{2}$ Universidade Estadual do Norte Fluminense, Centro de Ciências e Tecnologias Agropecuárias, Laboratório de Melhoramento Genético

Vegetal, Avenida Alberto Lamego, n 2.000, Horto, CEP: 28015-620 - Campos dos Goytacazes (RJ); wan_moreira@hotmail.com.

${ }^{3}$ Universidade do Estado de Mato Grosso, Departamento de Agronomia, Laboratório de Melhoramento de Plantas e Sementes, Rodovia

MT 358, Km 07, Jardim Aeroporto, CEP: 78300-000 - Tangará da Serra (MT).
} 


\section{INTRODUÇ̃̃O}

O Brasil é o maior produtor de frutas tropicais, haja vista possuir condições diversificadas de solo e clima. O abacaxi (Ananas comosus (L) Merril var. comosus Coppens \& Leal) vem se destacando entre as fruteiras cultivadas no mundo, alcançando a primeira posição em produção no ranking mundial (FAO, 2013).

A fruteira é classificada como semi perene, com um ciclo de produção que pode variar de 14 a 25 meses, onde condições edafoclimáticas, época de plantio, tipo e peso das mudas e práticas culturais adotadas possuem influência direta na produção final da cultura (PONCIANO et al., 2006).

Outro fator que também pode influenciar a produção de abacaxi é a ocorrência de doenças. A fusariose, causada pelo fungo Fusarium guttiforme Nirenberg \& O’Donnell, é considerada a doença de maior importância na cultura do abacaxizeiro no Brasil por possuir a capacidade de dizimar plantações inteiras. A doença é encontrada em todos os estados produtores da fruta no país, acarretando limitação da expansão da cultura (ZORZAL et al., 2008).

Para desenvolver técnicas de controle da doença é necessário conhecer o patógeno em questão. Dessa forma, o cultivo in vitro visa avaliar as melhores condições para o crescimento do fungo, analisando seu desenvolvimento em diferentes temperaturas, tempo de incubação, meio de cultura e fotoperíodo (AKINYELE; ADETUYI, 2005).

A partir do conhecimento das melhores condições para o desenvolvimento do fungo torna-se possível a multiplicação in vitro em larga escala, com o intuito de utilizar isolados em inoculações para identificar materiais resistentes, já que o plantio de cultivares com esta característica tem sido o método mais econômico e eficaz para se controlar a fusariose.

Diversos métodos de inoculação vêm sendo utilizados em avaliações da patogenicidade de diferentes espécies do gênero Fusarium. Metodologias que possam reproduzir seguramente sintomas da fusariose são ferramentas necessárias para compreender os aspectos fitopatogênicos do fungo. Por meio dessas ferramentas é possível realizar seleções de genótipos resistentes a serem empregados em programas de melhoramento visando desenvolver cultivares resistentes à fusariose, proporcionando redução de custos na produção (CASTRO et al., 2008).

A partir do exposto, este trabalho teve como objetivo avaliar o comportamento in vitro do fungo $F$. guttiforme em condições de temperatura e fotoperíodo distintos e determinar o método de inoculação mais eficiente para a avaliação da resistência de genótipos de abacaxizeiro à fusariose.

\section{MATERIAL E MÉTODOS}

Dois isolados foram obtidos de plantas com sintomas de fusariose coletadas nos municípios de Tangará da Serra $\left(14^{\circ} 39^{\prime} \mathrm{Sul}, 57^{\circ} 25^{\prime}\right.$ Oeste e altitude de $321,5 \mathrm{~m})$ e Terra Nova do Norte $\left(10^{\circ} 31^{\prime} 6^{\prime \prime}\right.$ Sul, 55 $5^{\circ} 13^{\prime} 56^{\prime \prime}$ Oeste e altitude de $310 \mathrm{~m}$ ) por serem regiões produtoras de abacaxi no Estado de Mato Grosso. As denominações adotadas foram ISO 1 para o isolado coletado no município de Tangará da Serra e ISO 2 em Terra Nova do Norte.

Fragmentos de tecidos sintomáticos foram previamente desinfestados em solução de hipoclorito de sódio a $2 \%$ por dois minutos, lavados em água destilada estéril e incubados em câmara úmida para indução de esporulação (MENEZES; ASSIS, 2004). A caracterização do microrganismo foi realizada através de chaves de identificação, a partir dos atributos macro e micromorfólogicos das culturas puras isoladas (NIRENBERG; O’DONNEL, 1998). Os indivíduos identificados como $F$. guttiforme foram submetidos ao teste de patogenicidade de acordo com método estabelecido por Santos et al. (2001) em folhas "D" destacadas de plantas resistentes (cv. Vitória) e suscetíveis (cv. Pérola) a fusariose. Os isolados que incitaram lesões sintomáticas de fusariose foram reisolados e confirmados como $F$. guttiforme.

Para a determinação do comportamento in vitro foram realizados experimentos separados para cada isolado. Ambos foram submetidos ao mesmo delineamento, condução e avaliação. O delineamento foi inteiramente casualizado em esquema fatorial $3 \times 3$ (três temperaturas e três fotoperíodos), com cinco repetições, onde cada parcela foi constituída de uma placa de Petri. Um disco de colônia do patógeno (7 $\mathrm{mm}$ ) foi transferido para cada placa de Petri contendo meio de cultura BDA (batata dextrose ágar) e incubados a 20,25 e $30^{\circ} \mathrm{C}$ sob três fotoperíodos $(0,12$ e 24 horas $)$.

A avaliação do índice de crescimento micelial (ICM) foi efetuada através de mensurações em dois eixos ortogonais a cada 48 horas por 10 dias. As médias foram utilizadas para avaliar o ICM conforme adaptação de Oliveira (1991).

$$
\mathrm{ICM}=\frac{\mathrm{C} 1+\mathrm{C} 2+\mathrm{C} 3+\mathrm{C} 4+\mathrm{C} 5}{\mathrm{~N} 2+\mathrm{N} 4+\mathrm{N} 6+\mathrm{N} 8+\mathrm{N} 10}
$$

onde $\mathrm{C} 1, \mathrm{C} 2, \mathrm{C} 3, \mathrm{C} 4$ e $\mathrm{C} 5$ são os crescimentos das colônias nas avaliações e N2, N4, N6, N8 e N10 os dias avaliados.

A análise da produção de conídios (PC), adaptada de Martelleto (1995), foi constituída por meio da contagem de macro e microconídios em câmera de Neubauer ao final de cada avaliação do crescimento micelial. Foram retirados quatro discos de micélio de sete milímetros de diâmetro das bordas das colônias de cada repetição e transferidos para tubos de ensaio contendo $20 \mathrm{~mL}$ de água destilada estéril, agitados para promover o desprendimento dos conídios.

Para a avaliação dos métodos de inoculação foi realizado um experimento em delineamento intei- 
ramente casualizado, com arranjo fatorial $3 \times 4$ (métodos $\mathrm{x}$ distância de inoculação). Folhas $\mathrm{D}$ de abacaxizeiro da cv. Pérola foram inoculadas a 2, 5, 8 e 11 centímetros da base pelos métodos de palito infestado com estruturas do patógeno (PI), disco de micélio sem ferimento na folha (DSF) e disco de micélio com ferimento (DCF). Para cada tratamento foram utilizadas cinco folhas destacadas da cultivar avaliada.

O método do disco de micélio utilizado foi conforme Tolêdo-Souza e Costa (2003), com testemunhas inoculadas por discos de BDA sem micélio, e para o método do palito infestado com estruturas do patógeno (CAMARGO; BARACHO, 1977) a testemunha constou da inoculação de palito umedecido em água destilada estéril, sem o patógeno. Aos 15 dias após a inoculação (DAI) foi realizada a mensuração dos maiores e menores diâmetros da lesão causada pelo patógeno.

Foi realizada análise de variância individual para cada experimento e para cada característica avaliada. A comparação de médias foi feita pelo teste de Scott-Knott a 5\% de probabilidade, utilizando o programa SISVAR (FERREIRA, 2011). Também foi realizada análise conjunta entre os experimentos $1 \mathrm{e}$ 2 para comparar os isolados.

\section{RESULTADOS E DISCUSSÃO}

$\mathrm{Na}$ comparação dos isolados pela análise conjunta não houve diferença significativa $(\mathrm{P} \leq 0,01)$ tan- to para a característica índice de crescimento micelial quanto para a produção de conídio. Os isolados coletados em regiões geográficas que apresentam características distintas, sendo Tangará da Serra (bioma cerrado) e Terra Nova do Norte (bioma amazônico), demonstraram o mesmo comportamento in vitro.

Houve interação significativa $(\mathrm{P} \leq 0,01)$ na fonte de variação fotoperíodo $\mathrm{x}$ temperatura para $\mathrm{o}$ ISO 1 e ISO 2, considerando-se as características ICM e PC.

Verifica-se, para o ISO 1, que a temperatura de $25^{\circ} \mathrm{C}$ proporcionou o maior ICM em todos os fotoperíodos. Já para o ISO 2 essa temperatura só ocasionou o melhor ICM quando submetida ao fotoperíodo de $0 \mathrm{~h}$, o qual apresentou diferença significativa para os fotoperíodos de 12 e $24 \mathrm{~h}$ (Tabela 1 ).

$\mathrm{Na}$ interação fotoperíodo $\mathrm{x}$ temperatura do ISO 1 observou-se que o fotoperíodo de $24 \mathrm{~h}$ proporcionou o maior crescimento encontrado a $20^{\circ} \mathrm{C}$ igual a $39,3 \mathrm{~mm}$, ICM este inferior aos observados nas temperaturas de 25 e $30^{\circ} \mathrm{C}$ para o mesmo fotoperíodo, indicando que esta temperatura acarreta limitações no desenvolvimento de F. guttiforme. Para a temperatura de $25^{\circ} \mathrm{C}$ os fotoperíodos que ocasionaram maior ICM foram 0 e $12 \mathrm{~h}$, sem diferirem entre si. Já para a incubação a $30^{\circ} \mathrm{C}$ não houve diferença significativa entre os fotoperíodos analisados. Os coeficientes de variação (CV\%) para a avaliação do crescimento micelial variou entre 13,66 a 24,18 .

Tabela 1. Índice de crescimento micelial $(\mathrm{mm})$ dos isolados 1 e 2 de $F$. guttiforme submetidos a diferentes fotoperíodos e temperaturas. Tangará da Serra (MT), 2013.

\begin{tabular}{ccccc}
\hline \multirow{2}{*}{ Isolados } & \multirow{2}{*}{ Fotoperíodo (horas) } & \multicolumn{3}{c}{ Temperatura } \\
\cline { 3 - 4 } & & $20^{\circ} \mathrm{C}$ & $25^{\circ} \mathrm{C}$ & $30^{\circ} \mathrm{C}$ \\
\hline \multirow{2}{*}{1} & 0 & $36,8 \mathrm{bC}$ & $44,2 \mathrm{aA}$ & $41,4 \mathrm{aB}$ \\
& 12 & $34,1 \mathrm{cC}$ & $44,0 \mathrm{aA}$ & $42,0 \mathrm{aB}$ \\
& 24 & $39,3 \mathrm{aB}$ & $40,7 \mathrm{bA}$ & $41,4 \mathrm{aA}$ \\
\hline \multirow{2}{*}{2} & 0 & $36,1 \mathrm{bC}$ & $44,6 \mathrm{aA}$ & $41,1 \mathrm{bB}$ \\
& 12 & $34,5 \mathrm{cC}$ & $42,2 \mathrm{bB}$ & $43,4 \mathrm{aA}$ \\
& 24 & $39,6 \mathrm{aC}$ & $41,8 \mathrm{bB}$ & $43,0 \mathrm{aA}$ \\
\hline
\end{tabular}

1/Médias seguidas pela mesma letra em maiúsculo na linha e minúsculo na coluna não diferem estatisticamente entre si pelo teste de Scott-Knott ao nível de 5\% de probabilidade.

Para o ISO 2 a temperatura de $20^{\circ} \mathrm{C}$ também limitou o crescimento do patógeno, sendo que o maior ICM foi no fotoperíodo $24 \mathrm{~h}$. Para a temperatura de $30^{\circ} \mathrm{C}$ o crescimento foi estatisticamente igual nos fotoperíodos 12 e $24 \mathrm{~h}$.

Costa et al. (2009) ao analisar crescimento micelial de $F$. guttiforme em diferentes temperaturas e fotoperíodos constataram que a temperatura de $25^{\circ} \mathrm{C}$ sob fotoperíodo de 12 horas são as condições ideais para o maior crescimento deste patógeno.

Martelleto (1995) avaliou diferentes temperaturas $\left(5,10,15,20,25\right.$ e $\left.30^{\circ} \mathrm{C}\right)$ sobre o desenvolvimento micelial em folhas destacadas e inoculadas com o patógeno e constatou que houve crescimento micelial na faixa de 10 a $30^{\circ} \mathrm{C}$, mas a temperatura considerada ótima foi a de $25^{\circ} \mathrm{C}$.

Silva-Acuña et al. (1995) em análises do crescimento de $F$. guttiforme em folhas D nas temperaturas $5,10,15,20,25,30$ e $35^{\circ} \mathrm{C}$ sob ausência luminosa constataram que o melhor desenvolvimento radial da lesão ocorreu entre 25 e $30^{\circ} \mathrm{C}$. Para as temperaturas de 5 e $35^{\circ} \mathrm{C}$ não houve crescimento do patógeno.

Nas avaliações de produção de conídios (PC) foi constatado que para o ISO 1 as temperaturas de 20 e $30{ }^{\circ} \mathrm{C}$ não apresentaram diferença estatística entre os fotoperíodos, enquanto que a temperatura de $25{ }^{\circ} \mathrm{C}$ interagindo com o fotoperíodo de $12 \mathrm{~h}$ dis- 
tinguiu-se, apresentando o maior valor em produção de conídios. Em relação ao ISO 2 verificou-se que os maiores valores de PC foram produzidos nas três temperaturas sob fotoperíodo de 12 horas, ressaltando que para $30^{\circ} \mathrm{C}$ a condição de 12 e $24 \mathrm{~h}$ não diferiram estatisticamente entre si (Tabela 2).

Tabela 2. Produção de conídios $\left(10^{4} \mathrm{~mL}^{-1}\right)$ dos isolados 1 e 2 de $F$. guttiforme submetidos a diferentes fotoperíodos e temperaturas.

\begin{tabular}{ccccc}
\hline \multirow{2}{*}{ Isolados } & \multirow{2}{*}{ Fotoperíodo (horas) } & \multicolumn{3}{c}{ Temperatura } \\
\cline { 3 - 5 } & 0 & $20^{\circ} \mathrm{C}$ & $25^{\circ} \mathrm{C}$ & $30^{\circ} \mathrm{C}$ \\
\hline \multirow{2}{*}{1} & 12 & $1,92 \mathrm{aA}$ & $3,69 \mathrm{bA}$ & $2,44 \mathrm{aA}$ \\
& 24 & $2,44 \mathrm{aB}$ & $12,91 \mathrm{aA}$ & $3,28 \mathrm{aB}$ \\
& 0 & $0,59 \mathrm{aB}$ & $2,48 \mathrm{bA}$ & $3,17 \mathrm{aA}$ \\
\hline \multirow{2}{*}{2} & 12 & $1,44 \mathrm{bA}$ & $1,84 \mathrm{bA}$ & $1,83 \mathrm{bA}$ \\
& 24 & $2,61 \mathrm{aC}$ & $16,45 \mathrm{aA}$ & $4,10 \mathrm{aB}$ \\
& $0,98 \mathrm{bB}$ & $2,64 \mathrm{bA}$ & $3,05 \mathrm{aA}$ \\
\hline
\end{tabular}

${ }^{1 /}$ Médias seguidas pela mesma letra em minúsculo na coluna e maiúsculo na linha não diferem estatisticamente entre si pelo teste de Scott-Knott ao nível de 5\% de probabilidade.

Para a fonte de variação fotoperíodo, os dois isolados não diferiram estatisticamente entre as temperaturas, quando incubados sob fotoperíodo $0 \mathrm{~h}$. $\mathrm{Na}$ condição de $12 \mathrm{~h}$ apresentaram maior produção de conídios a $25^{\circ} \mathrm{C}$ e a $24 \mathrm{~h}$ nas temperaturas de 25 e $30^{\circ} \mathrm{C}$. Para a variável produção de conídio as maiores concentrações foram obtidas na temperatura $25^{\circ} \mathrm{C}$ com fotoperíodo $12 \mathrm{~h}$ para os dois isolados, indicando ser esta a melhor condição de propagação de $F$. guttiforme. Os coeficientes de variação encontrados na variável PC variaram entre 13,10 a 19,05\%.

Para a determinação do comportamento in vitro de $F$. guttiforme sugere-se que não avalie somente o ICM, mas também a PC, pois o patógeno pode vir a desenvolver alto índice de ICM com baixa PC. Segundo Nozaki et al. (2004), as condições que favorecem o crescimento micelial do fungo não sempre são as mesmas para a esporulação, pois a luz em efeito direto sobre o fungo pode induzir ou inibir a formação de estruturas reprodutivas.

Ao relacionar o ICM dos isolados com a PC pode-se observar que este fungo exerce maior ameaça ao cultivo nas épocas que apresentam temperatu- ras ambientais de $25^{\circ} \mathrm{C}$. A temperatura média do município de Tangará da Serra e de Terra Nova do Norte, duas das regiões produtoras de abacaxi do Mato Grosso, é de $24^{\circ} \mathrm{C}$ para ambos (COLETTI et al., 2012). Portanto, os dois locais proporcionam um ambiente ótimo (umidade relativa e temperatura) para o desenvolvimento do fungo. Segundo Andrade et al. (2010), a temperatura é um dos fatores que mais influenciam no crescimento micelial dos fungos.

$\mathrm{Na}$ avaliação dos métodos e das distâncias de inoculação foi observada diferença significativa $(\mathrm{P} \leq 0,01)$ apenas para métodos de inoculação.

$\mathrm{O}$ método do palito infestado com estruturas do patógeno (PI) proporcionou a maior área lesionada, seguido do método disco de micélio com ferimento (DCF) e do disco de micélio sem ferimento (DSF) (Tabela 3). Pode-se observar que a inoculação por palito infestado se mostrou mais eficiente, promovendo a inexistência de escape, maiores reações sintomáticas nas plantas e a possibilidade de avaliar as lesões quantitativamente, com fácil execução.

Tabela 3. Área lesionada por $F$. guttiforme em folhas D destacadas de abacaxi, cv. Pérola, pelos métodos palito infestado, disco de micélio sem ferimento e disco de micélio com ferimento.

\begin{tabular}{lc}
\hline \multicolumn{1}{c}{ Método de Inoculação } & Área lesionada $\left(\mathrm{cm}^{2}\right)$ \\
\hline Palito infestado com estruturas do patógeno & 2,58 \\
Disco de micélio sem ferimento & 0,14 \\
Disco de micélio com ferimento & 1,23 \\
\hline
\end{tabular}

A eficácia da inoculação em folhas destacadas usando palito infestado com estruturas do patógeno também foi evidenciada por Santos et al. (2001), que avaliaram oito métodos de inoculação, quais sejam: palito contaminado posição perpendicular; palito contaminado posição longitudinal; disco de colônia sobre ferimento; disco de colônia sobre ferimento + algodão umedecido na face adaxial; disco de colônia sobre ferimento + algodão umedecido na extremidade da folha; disco de colônia sobre ferimento + proteção com esparadrapo; algodão umedecido na suspensão de inóculo; e injeção da suspensão conidial no mesófilo de Fusarium subglutinans (atualmente classificado como $F$. guttiforme) em diferentes folhas de abacaxizeiro cv. Pérola, com possibilidade de avaliação a partir dos 15 dias após inoculação. Resultados semelhantes foram obtidos por Oliveira et al (2011) ao avaliarem dois métodos de inoculação (palito contaminado e disco de micélio sobre ferimento) em folhas D destacadas de abacaxi (cv.Pérola) em diversas condições e posições (proteção com fita adesiva, algodão umedecido, posição longitudinal e perpendicular) nas distâncias 2 e $5 \mathrm{~cm}$ da base da folha e constataram que os maiores desenvolvimentos de 
sintomas foram observados nos tratamentos disco de colônia do patógeno, sobre ferimento a $2 \mathrm{~cm}$ da base com fita adesiva transparente e com algodão umedecido na extremidade da folha a $5 \mathrm{~cm}$ da base, e palitos contaminados com o patógeno na posição perpendicular a $5 \mathrm{~cm}$ e $2 \mathrm{~cm}$ da base.

Ao relacionar o método DCF com o DSF pode-se comprovar a necessidade da realização de ferimentos no local a ser inoculado pelo fato do DCF ter proporcionado maior lesão que DSF. O método DCF apresentou a particularidade de escape nas análises, característica esta não desejável na seleção de um bom método de avaliação. Esse resultado está de acordo com a afirmação de Matos e Cabral (2005), o qual para ocorrer infecção de $F$. guttiforme no abacaxizeiro é necessário que existam aberturas naturais ou ferimentos na superfície da planta. Nos frutos a infecção ocorre através das flores abertas durante o desenvolvimento das inflorescências.

A avaliação das distâncias de inoculação a 2, 5,8 e $11 \mathrm{~cm}$ da base da folha $\mathrm{D}$ não apresentaram diferença significativa $(\mathrm{P} \leq 0,01)$. Portanto, inoculações em folhas D para identificação de acessos resistentes a fusariose podem ser realizadas entre 2-11 centímetros da base da folha. Da mesma forma, Oliveira et al. (2011) ao avaliarem dois métodos de inoculação (palito contaminado e disco de micélio com ferimento) de $F$. guttiforme nas distâncias de 2 e $5 \mathrm{~cm}$ constataram que estas distâncias não apresentaram diferença significativa entre si.

\section{CONCLUSÕES}

Não houve diferença no comportamento in vitro entre os isolados.

A temperatura e fotoperíodo recomendados para a multiplicação de $F$. guttiforme é de $25^{\circ} \mathrm{C}$ sob 12 horas, respectivamente.

O método indicado para avaliação de resistência por meio de inoculação é o do palito infestado com estruturas do patógeno a uma distância entre 2 e $11 \mathrm{~cm}$ da base da folha.

Para que ocorra a infecção do patógeno F. guttiforme torna-se necessário a realização de ferimento no local a ser inoculado.

\section{AGRADECIMENTOS}

À Fundação de Amparo à Pesquisa do Estado de Mato Grosso (FAPEMAT) pelo financiamento do projeto de pesquisa, à Coordenação de Aperfeiçoamento de Pessoal de Nível Superior (CAPES) e a Rede PRO-CENTRO-OESTE pela concessão da Bolsa de Mestrado.

\section{REFERÊNCIAS}

AKINYELE, B. J.; ADETUYI, F. C. Effect of agrowastes $\mathrm{pH}$ and temperature variation on the growth of Volvariella volvacea. African Journal of Biotechnology, Nairobi, v. 4, n. 12, p. 1390-1395, 2005.

ANDRADE, M. C. M. et al. Crescimento micelial in vitro de cinco linhagens de Agaricus bisporus submetidas a diferentes condições de temperatura. Acta Scientiarum Agronomy, Maringá, PR. v. 32, n. 1, p. 69-72. 2010.

CAMARGO, L. M. P. C. A.; BARACHO, I. R. Virulência de linhagens de Fusarium moniliforme Sheld. var. subglutinans Wr. e Rg. Summa Pytopathologica, Piracicaba,SP. v. 3, n. 3, p. 215 - 220, 1977.

CASTRO, N. R. et al. Occurrence, inoculation methods and aggressivity of Fusarium oxysporum f. sp. cubense in Heliconia spp. Summa Phytopathologica, Botucatu,SP. v. 34, n. 2, p.127-130, 2008.

COLETTI, A. J. et al. Evapotranspiration and culture coefficient of oil seed plant Jatropha curcas. Revista Agrarian. Dourados, v 5, n 18, p. 373-383. 2012.

COSTA, N. F. P.; FERREIRA, I. C. P. V.; AQUINO, C. F.; ARAÚJO, A. V.; SALES, N. L. P. Crescimento micelial de Fusarium subglutinans $f$ sp. ananás em diferentes temperaturas. Instituto de Ciências agrárias/UFMG, Montes Claros-MG. 2009. In: Congresso Brasileiro de Fitopatologia .42. 2009, Pelotas, RS. Anais...Pelotas, RS. 2009.

FAO. Food and Agriculture Organization of the United Nations. Disponível em: http://www.fao.org/ home/en/. Acesso em 10 de maio de 2015.

FERREIRA, D. F. Sisvar: a computer statistical analysis system. Ciência \& Agrotecnologia, Lavras, v. 35, n. 6, p. 1039-1042, 2011.

MARTELLETO, L. A. P. Incitante da fusariose do abacaxizeiro (Ananas comosus (L.) Merril) e sobre o efeito da temperatura ambiente no seu desenvolvimento. 1995. $91 \mathrm{f}$. Dissertação (Mestrado em fitossanidade) - Universidade Federal Rural do Rio de Janeiro, Rio de Janeiro.1995.

MATOS, A. P. DE; CABRAL, J. R. S. Manejo integrado da fusariose do abacaxizeiro. Cruz das Almas: Embrapa-CNPMF, 2005. 2 p. (EmbrapaCNPMF, Abacaxi em Foco n. 32).

MENEZES, M; ASSIS, S. M. P. Guia Prático para fungos fitopatogênicos. $2^{\mathrm{a}}$ edição, imprensa universitária, UFRPE, Recife-PE. 120 p. 2004. 
NIREMBERG, H.I.; O'DONNELL, K. New Fusarium species and combinations within the Gibberella fujikuroi species complex. Micologia, Bronx, NY, v.90, n.3, p. 434-458. 1998.

NOZAKI, M. H.; CAMARGO, M. E. ; BARRETO, M. Caracterização de Diaporthe citri em diferentes meios de cultura, condições de temperatura e luminosidade. Fitopatologia Brasileira, Brasília, v. 29, n.4, p. 429-432, 2004.

OLIVEIRA, J. A. Efeito do tratamento fungicida em sementes e no controle de tombamento de plântulas de pepino (Cucumis sativus L.). 1991. 111f. Dissertação (Mestrado em fitossanidade). Lavras: Universidade Federal de Lavras, Lavras, 1991.

OLIVEIRA, M. D. M; LEITE, L. C.N; PEREIRA, R. Incidência de fusariose e avaliação de métodos de inoculação de Fusarium gutiforme em folhas de abacaxizeiro. Revista Caatinga, Mossoró, v. 24, n. 1, p. 137-142. 2001.

PONCIANO, N. J. et al. Avaliação econômica da produção de abacaxi (Ananas comosus L.) cultivar Pérola na região Norte Fluminense. Revista Caatinga, Mossoró, v. 19, n.1, p. 82-91, 2006.

SANTOS, R. L. M. S.; MATOS, A. P. de; CABRAL, J. R. S. Avaliação da infecção com Fusarium subglutinans em diferentes tipos de folhas de abacaxizeiro. Magistra, Cruz das Almas, v. 13, n. 1, p. 1$50,2001$.

SILVA-ACUÑA, R.; COSTA, A. F.; BARRETO, M. Efeito da temperatura e do tipo de folha no desenvolvimento de lesões de Fusarium subglutinans f. sp. ananas no abacaxizeiro 'Pérola'. Fitopatologia Brasileira, Brasília, v. 20, n. 3, p. 498-500, 1995.

TOLÊDO-SOUZA, E. D. de; COSTA, J. L. da S. Métodos de inoculação de plântulas de feijoeiro para avaliação de germoplasma quanto à resistência a Sclerotinia sclerotiorum (Lib.) De Bary. Pesquisa Agropecuária Tropical, Goiânia, v. 33, n. 2, p. 5763, 2003.

ZORZAL, P. B; AQUIJE, G. M. F. V.; VENTURA, J. A.; FERNANDES, A.R.; FERNANDES, P.M.B. Análise Morfológica e Bioquímica Comparativa da Resistência a Fusariose em Abacaxizeiro. In: XX CONGRESSO BRASILEIRO DE FRUTICULTURA, 2008, Vitória. Anais... Vitória, ES, 2008. 